\title{
ASPECTOS MORFOESCULTURAIS DO RELEVO ENTRE OS MUNICIPIOS DE COLIDER A PEIXOTO DE AZEVEDO - MT
}

\author{
Bruna da Cruz Andrade ${ }^{(\mathrm{a})}$, Fabio Junior do Espirito Santo Andrade, ${ }^{(\mathrm{b})}$ Marli Aparecida Ribeiro, ${ }^{(\mathrm{c})}$ \\ Leila Nalis Paiva da Silva Andrade. ${ }^{(d)}$
}

(a) Acadêmica do Curso de Licenciatura em Geografia da Universidade do Estado de Mato Grosso/Campus de Colider. Bolsista de Iniciação Científica/FAPEMAT. Integrante do Laboratório de Pesquisa e Ensino em Geomorfologia Fluvial “Antonio Christofoletti”. E-mail: bruna.c.andrade@ live.com

(b) Acadêmico do Curso de Licenciatura em Geografia da Universidade do Estado de Mato Grosso/Campus de Colider. Bolsista de Iniciação a Docência/PIBID. E-mail: fabio_junior.andrade@ hotmail.com

(c) Acadêmica do Curso de Licenciatura em Geografia da Universidade do Estado de Mato Grosso/Campus de Colider. E-mail: marlicolider@hotmail.com

(d) Doutoranda em Ecologia e Recursos Naturais pela Universidade Federal de São Carlos. Professora Assistente do Curso de Geografia da Universidade do Estado de Mato Grosso. Coordenadora do Laboratório de Pesquisa e Ensino em Geomorfologia Fluvial "Antonio Christofoletti". Coordenadora de área Geografia/Colider do Programa Institucional de Bolsa de Iniciação à Docência (PIBID/CAPES). E-mail: leilaandrade @ unemat.br

\section{EIXO: SISTEMAS GEOMORFOLÓGICOS: ESTRUTURA, DINÂMICAS E PROCESSOS}

\section{Resumo}

Os municípios de Colider e Peixoto de Azevedo estão localizados na depressão norte mato-grossense, em área de relevo suave ondulado ou ondulado passando pelo processo de aplanamento. A presente pesquisa teve como objetivo identificar os apectos morfoesculturais do relevo entre os municípios de Colider a Peixoto de Azevedo/Mato Grosso. A metodologia empregada constituiu em análise e observação do percurso distribuídos em três pontos, sendo analisado a forma de relevo presente e fatores modificadores da paisagem. No município de Peixoto de Azevedo foi observada uma área de mineração desativada, sendo possível avaliar como a extração de minério é prejudicial ao relevo. Ao longo do perfil pode-se perceber como as ações antrópicas estão contribuindo com mudanças no ambiente.

Palavras chave: Geomorfologia Urbana; Mineração; Erosão; Preservação Ambiental

\section{Introdução}

Os aspectos morfoesculturais do relevo contribuem com a modelagem da superfície terrestre. Os agentes externos agindo no processo de meteorização da rocha, no transporte e acumulação dos materiais constituintes. As mudanças que ocorre no ambiente são de ordem natural e podem ser acelerada pela ação antrópica, causando a erosão do solo, poluição (água, ar e solo), comprometendo todo um ecossistema. De acordo com Casseti (2005) o relevo tem papel fundamental no processo de ocupação do espaço, sendo que qualquer mudança pode interferir no comportamento da paisagem.

De acordo com Ross (1995, p. 231) “A mineração e o garimpo são atividade que também exerce forte interferência no meio natural e contribui para sua deterioração. Trata-se da extração de recursos naturais do solo e do subsolo dos mais variados tipos e uso". Dentro dos fatores geomorfológicos a mineração atua 


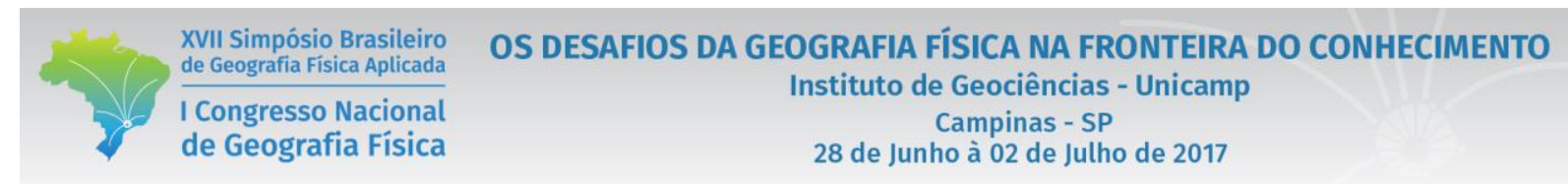

como grande modificador do relevo "Por se tratar da extração de recursos naturais não renováveis da crosta terrestre, a mineração geralmente é vista como uma atividade altamente impactante e não sustentável” (IBAMA 2001).

O trabalho teve como objetivo identificar os aspectos morfoesculturais do relevo entre os municípios de Colider a Peixoto de Azevedo/Mato Grosso. Abordando os processos geomorfológicos da região, visando observar os fatores modificadores do relevo, destacando a mineração, processo muito utilizado no município de Peixoto de Azevedo.

\section{Metodologia}

A pesquisa foi realizada entre os municípios de Colider e Peixoto de Azevedo/Mato Grosso, localizados ao norte do Estado, respectivamente. O relevo é caracterizado na depressão norte mato-grossense: suave e ondulado, sendo possível a observação de processos erosivos através da ação antrópica em três pontos do percurso estudado (Tabela 1).

Tabela 1. Localização dos pontos observados

\begin{tabular}{|c|c|c|c|}
\hline \multirow{2}{*}{ Pontos } & \multicolumn{2}{|c|}{ Coordenadas Geográficas } & \multirow{2}{*}{ Altitude (m) } \\
\cline { 2 - 3 } & Latitude Sul & Longitude Oeste & 346,3 \\
\hline I & $10^{\circ} 48^{\prime} 29^{\prime}$ & $55^{\circ} 15^{\prime} 33^{\prime}$ & 378 \\
\hline II & $10^{\circ} 50^{\prime} 43^{\prime}$ & $55^{\circ} 10^{\prime} 44^{\prime}$ & 289,3 \\
\hline III & $10^{\circ} 14^{\prime} 32,5^{\prime}$ & $55^{\circ} 00^{\prime} 45,5^{\prime}$ & \\
\hline
\end{tabular}

\subsection{Procedimentos metodológicos}

Para realização dessa pesquisa foi necessário trabalho de campo para observação e análise dos processos geomorfológicos. Sendo fundamental que antes da realização, fizesse pesquisas bibliográficas, leituras em artigos, livros e estudos para melhor interpretação dos processos.

\subsection{Trabalho de campo}

O campo foi realizado em dezembro de 2016, para reconhecimento e observação da área. Utilizou-se GPS para obter as coordenadas geográficas dos pontos estudados. Durante o percurso foram feitas observações da paisagem (solo, vegetação e relevo). A observação em campo é também ponderada como instrumento de coleta de dados para conseguir informações sobre determinados aspectos da realidade. Auxilia o pesquisador a "identificar e obter provas a respeito dos seus objetivos sobre os quais os indivíduos não 

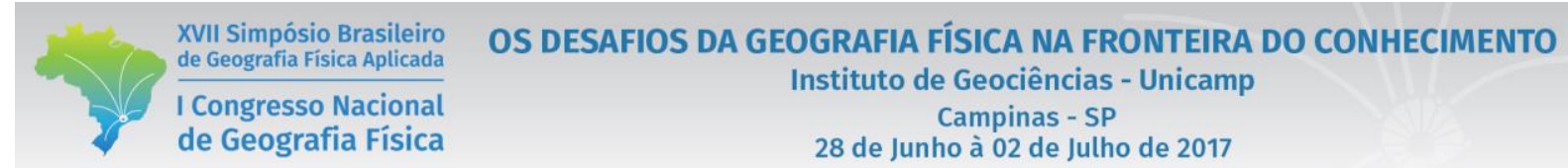

têm consciência, mas que orientam seu comportamento" (LAKATOS, 1996, p. 38). Proporciona ao pesquisador "o contato mais direto com a realidade" (BONI e QUARESMA, 2005, p. 68-78).

\section{Resultados e Discussão}

Colider está localizada ao norte de Mato Grosso com características de clima tropical com verão úmido e inverno seco. Seu relevo é suave ondulado, passando pelo processo de aplanamento. Peixoto de Azevedo é uma cidade de clima tropical, a temperatura varia entre 12 e $41^{\circ} \mathrm{C}$, seu relevo é plano ondulado com elevações formadoras das bacias dos rios Peixoto e Iriri (LUCIO, 2012). Os dados revelam que o rio Peixoto encontra-se em estado de degradação devido os produtos químicos lançado diretamente no canal com a prática da mineração e as Áreas de Preservação Permanente encontra-se parcialmente preservada.

No primeiro ponto a margem da MT 320 identificou-se área de dissecação onde está ocorrendo erosão, onde os materiais intemperizados estão sendo transportando para área de acumulação. Caracterizado pelo relevo de planalto residual a área está sendo utilizada para pastagem (Figura I).

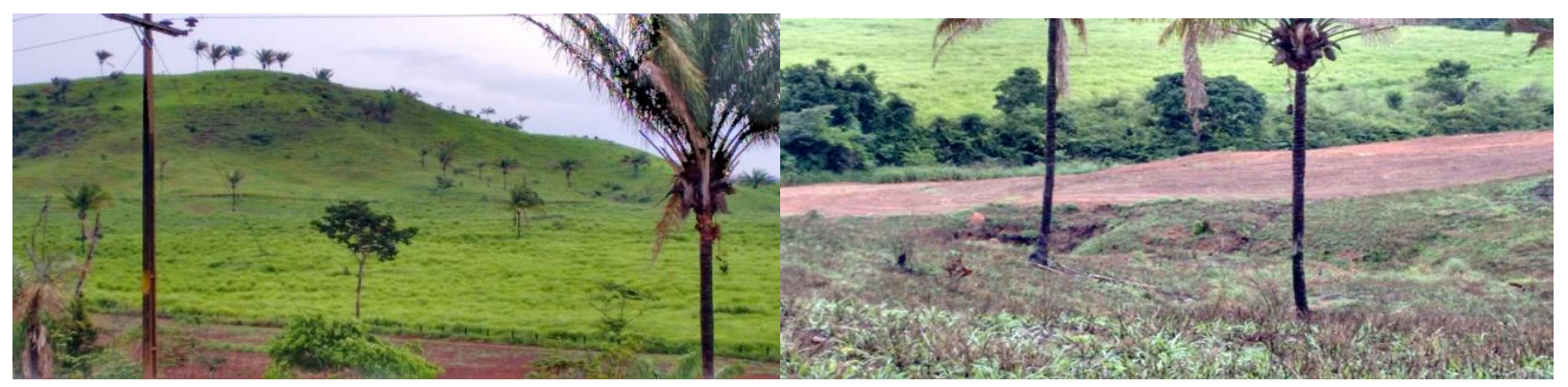

Figura I- Morro de colina

O segundo ponto foi trabalhado a Geomorfologia Urbana do município de Nova Santa Helena, com os tipos de construções existentes no local. O relevo da região é caracterizado por uma área de vale. Pode-se observar ocupação irregular em áreas elevadas. Essa ação antrópica contribui com o surgimento de ravinas (Figura II)

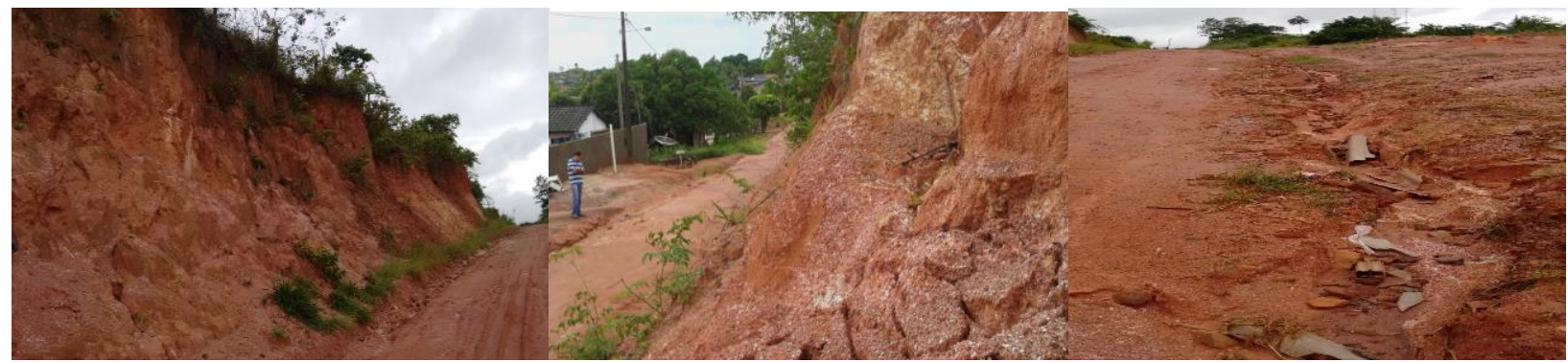

Figura II - Morro de Nova Santa Helena 
O processo erosivo nessa área está ocorrendo devido a composição do solo e sendo intensificado com a intervenção do gado e a ação antrópica desenvolvidas no entorno. Casseti (2005) afirma que o $6^{\circ}$ táxon corresponde as pequenas formas de relevo que se desenvolve por interferência antrópica direta ou indiretamente ao longo das vertentes. Reforçando o conceito Ross (1992) ressalta que são forma geradas pelo processo erosivo e acumulativo atuais: como ravina, voçoroca, corrida de lama, assoreamento, dentre outros.

Segundo Ross (2014) quando as águas atingem os setores dos vales de menor inclinação, aproximando-se dos chamados níveis de base, ocorre os processos de sedimentação, primeiro são depositados os sedimentos mais grosseiro e pesado, depois os finos e leve.

No terceiro ponto no município de Peixoto de Azevedo pode-se observar a área que foi destinada ao garimpo, atualmente desativada. O relevo é caracterizado como suave ondulado, a vegetação encontra-se parcialmente preservada, onde pode-se identificar uma vegetação rasteira e pouca vegetação de pequeno e médio porte (Figura III).

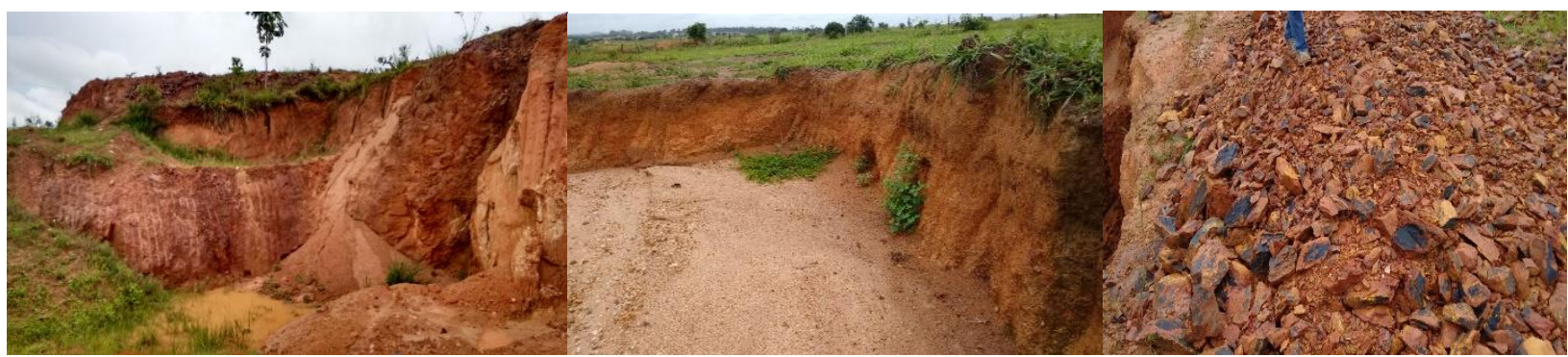

Figura III- área de mineração

$\mathrm{Na}$ área pode-se observar a escavação feita pelo homem no processo da mineração o que contribuiu com a erosão por voçorocamento. O garimpo está instalado ao lado da área de nascente do rio Peixoto. Nessa área foram encontrados diversos tipos de rochas: sedimentares (folhelho e conglomerado) e metamórfica (quartzito).

No estado de Mato Grosso o garimpo teve seu auge no município de Poconé. Essa atividade teve os incentivos dos projetos de assentamentos na Amazônia nos anos 70 e 80, como proposta de povoar áreas de desenvolver a agricultura familiar na terra (LEONEL, 1988). 


\section{Conclusão}

Trabalhar o ambiente de maneira holística e integrada contribui para discussões em relação ao ambiente. Nas áreas observadas o relevo está caracterizado pela depressão norte mato-grossense: suave e ondulado. As ações antrópicas desenvolvidas na área estão contribuindo com a degradação do ambiente. Desta forma, têm-se a necessidade de outros estudos, para que assim se possam propor medidas de preservação ambiental.

\section{Agradecimentos}

Os autores agradecem ao projeto "Bacia hidrográfica do rio Teles Pires: dinâmica fluvial e empreendimentos hidroelétricos entre os municípios de Nova Canaã do Norte e Itaúba, Mato Grosso", financiado pelo Edital Universal 005/2015 da Fundação de Amparo à Pesquisa do Estado de Mato Grosso - FAPEMAT, pelo apoio financeiro e pelas bolsas de Iniciação Científica. À Coordenação de Aperfeiçoamento de Pessoal de Nível Superior (CAPES), pela concessão de Bolsa de Institucional de Iniciação a Docência. Também à Universidade do Estado de Mato Grosso (UNEMAT).

\section{Bibliografia}

BONI, V; QUARESMA, S. J. Aprendendo a entrevistar: como fazer entrevistas em Ciências Sociais. Revista Eletrônica dos Pós-Graduandos em Sociologia Política. Universidade Federal de Santa Catarina. Janeirojulho/2005, p. 68-80. Disponível em: <http://www.emtese.ufsc.br/3_art5.pdf >. Acesso em: 10 de fevereiro de 2017. CASSETI, V. Geomorfologia. [S.1.]: [2005]. Disponível em: <http://www.funape.org.br/geomorfologia/>. Acesso em: 15 Janeiro 2017

IBAMA. MINISTÉRIO DO MEIO AMBIENTE (2001) Disponivel em: <http://www.mma.gov.br/estruturas/sqa pnla/_arquivos/MANUAL_mineracao.pdf > acesso em 12 Janeiro 2017

LAKATOS, E. M.; MARCONI, M. de A. Técnicas de pesquisa. 3. ed. São Paulo: Atlas, 1996, p. 20.

LEONEL, M. A morte social dos rios. São Paulo: Perspectiva Instituto de Antropologia e Meio Ambiente: FAPESP, 1998 - (Coleção Estudos), p. 95-139.

LUCIO, Geraldo. Conheça um pouco Sobre o Município de Peixoto de Azevedo - Mato Grosso- Brasil. Turismo Rural Mato Grosso 2012. Disponível em: < http://www.turismoruralmt.com/2011/07/conheca-um-pouco-sobre-omunicipio-de.html > acesso em: 16 janeiro 2017

ROSS, J. L. S. O registro cartográfico dos fatos geomorfológicos e a questão da taxonomia do relevo. Revista do Departamento de Geografia. n. 6, p. 17-29, 1992.

ROSS, J. L. S. Análises e Sínteses na Abordagem Geográfica da Pesquisa para o Planejamento Ambiental. Revista do Departamento de Geografia da USP. São Paulo. n.9, p.65-75, 1995.

ROSS, J. L. S. Geografia do Brasil. - 6. Ed., 2. reimpr. - São Paulo: Editora da Universidade de São Paulo, 2014. 